\title{
Perception Based Determinants of Mobility Dilemma in Ilorin Metropolis
}

\author{
Abdulmajeed Olaremi Shittu, Muhammad Zaly Shah, Muhammad Ali Chiroma \\ Department of Urban and Regional Planning, Faculty of Built Environment, Universiti Teknologi Malaysia, \\ Johor Bahru, Malaysia \\ Email: shittuabdulmajeed@yahoo.ca
}

Received 18 March 2015; accepted 3 April 2015; published 7 April 2015

Copyright (C) 2015 by authors and Scientific Research Publishing Inc.

This work is licensed under the Creative Commons Attribution International License (CC BY). http://creativecommons.org/licenses/by/4.0/

(c) (i) Open Access

\begin{abstract}
Usually, planning proceeds from issue identification and evaluation, directed at addressing recognized problems. As straightforward as it sounds, this sometimes can be difficult to achieve in settings where outdated master plans, continuous piecemeal and poorly regulated development are the order of the day. Even worse is the near total lack of baseline data upon which rational decisions about issues, such as mobility can be premised. Resulting into a scenario where holistic evaluations of city mobility needs and requirements are sometimes entirely jeopardized, leaving city managers with very little information to work with. The consequence is a distress filled mobility environment, from which determinants of dilemma may be tacitly admitted, but are generally not properly determined. This work uses perception of travelers' to rank and classify effect of contextually relevant mobility influencing attributes of Ilorin metropolis, as bases for isolating determinants of mobility dilemma in the city. The approach is targeted at providing city managers with a simplistic alternative way of evaluating needs, based upon user identified preferences, such that determinants of mobility dilemma become implicit enough to be utilized for decision making and planning. The work involved a survey of randomly selected respondents' from officially designated spatial subunits of Ilorin metropolis. It became apparent that attributes of public modes, development characteristics, as well as other operational, economic and safety attributions of the city's mobility environment were influencing perception of mobility by respondents' negatively, mainly as an offshoot of inadequate planning and regulation enforcement in the city. It is suggested that, parsimonious techniques such as utilized in this work, be employed in bridging the gap between comprehensive plans, where wherewithal is lacking.
\end{abstract}

\section{Keywords}

Perception of Mobility, Determinants of Mobility Dilemma, Mobility Environment, Mobility Needs, Mobility Evaluation 


\section{Introduction}

Since Ravenstein 1885 work [1], the movement of people has been an active subject of research in the social and geographical sciences. It has been shown in quantitative studies and described in a broad range of representations that a close relationship exists between mobility, distance and the environment within which it happens [2]. No doubt, the efficacy of complex quantitative mobility evaluation in divulging useful mobility underpinnings has been proven. However, their lack of altruistic and realistic connections to mobility complexities continues to be demerits. The increasing complexity [3] [4] and high technical requirements associated with running simulations with contemporary tools bring about drawbacks in data deficient situations, characteristic of developing nations, such as Nigeria. A drawback premised on data unavailability, "dirtyness" or scantiness. The situation is further compounded because the temporal and economic cost of gathering basic data for use in dedicated databases present other challenges in these settings. This is particularly so because the average data deficient city usually lacks the resources to embark on full scale, world class data acquisition programmes or projects. Consequently, how mobility goes on in data deficient cities of developing nations are usually inadequately described, especially at the city and sub-city levels. This trend perpetually keeps mobility environment cumbersome and full of myriad issues that result into different levels of mobility dilemma for different stratum of the society, typically underscored by socio-economic, physical, environmental and political impulses that in turn help to aggravate the severity of mobility dilemma an individual experiences.

Therefore, it becomes pertinent to seek parsimonious but reliable approaches to assessing or describing how mobility goes on in such areas, so as to create a viable decision support platform for city management, especially by local authorities. One way of gaining this insight is by tapping into the perception of travel by the traveler, from which engendered inhibitors and enhancers of mobility in the environment can be deciphered. Perception entails acquiring and mentally interpreting information from the senses, in other to discern. Perception connotes a person's ability to be aware of and understand what is happening in his or her environment [5]. A number of factors operate to shape perception [6], these factors can reside in the perceiver, the object being perceived or in the context of the situation, in which perception happens [7]. An interesting attribute of perception is its incremental adaptableness, it reshapes according to new knowledge and developments a perceiver is exposed to.

Many perception based urban studies have been carried out to determine a number of issues. For instance, to gain insight into the determinants of cycling to school, [8] used school pupil's parent's perception of cycling routes in socio-ecological models to identify correlates at multiple levels (individual, social and physical environmental factors) [9], also used perception of traffic to demonstrate that demographic and environmental factors, such as traffic and busy roads, can determine whether an individual's perception of an environment within which mobility takes place is negative or positive. Likewise, a study on a walking intervention programme, towards creating safe walking routes to school in a rural area of California, USA, succeeded in increasing walking rates to school, by using perception based criteria to identify needed interventions [10]. It can therefore be said that perception is key to the process of understanding our environment and how it influences us. Hence, discerning underlining determinants of a group of people's perception of an environment, and the elements it contains, may reveal traits that could further help in understanding such an environment, for the purpose of maintaining, reconstructing or administering it. These works provide some bases why tapping into the perception of travelers, who genuinely know how the travel environment enhances or hinders their personal mobility is essential.

\section{Methodology}

\subsection{The Study Area}

Ilorin is a metropolitan area in Kwara state, north central Nigeria. The city exhibits characteristic dualism similar to many developing country cities [11]. Thus, Ilorin can be taken as a fair representation of cities in developing countries, more so Nigeria. The city has both organic and inorganic sectors, reflecting both modern and traditional characteristics. The city also suffers from inadequate planning data base, as attested to by [12]. Ilorin, to a large extent exhibits homogeneity in terms of development density, environmental quality, and in transport enterprises [13]. Efforts to provide adequate transport infrastructure for the city of Ilorin have been adjudged adhoc, uncoordinated and poor according to [14], which is why simplistic alternative approaches are required to enable local city managers better address issues related to mobility experiences and dilemma in the city. Figure 1, depicts Ilorin in the context of Kwara state. 


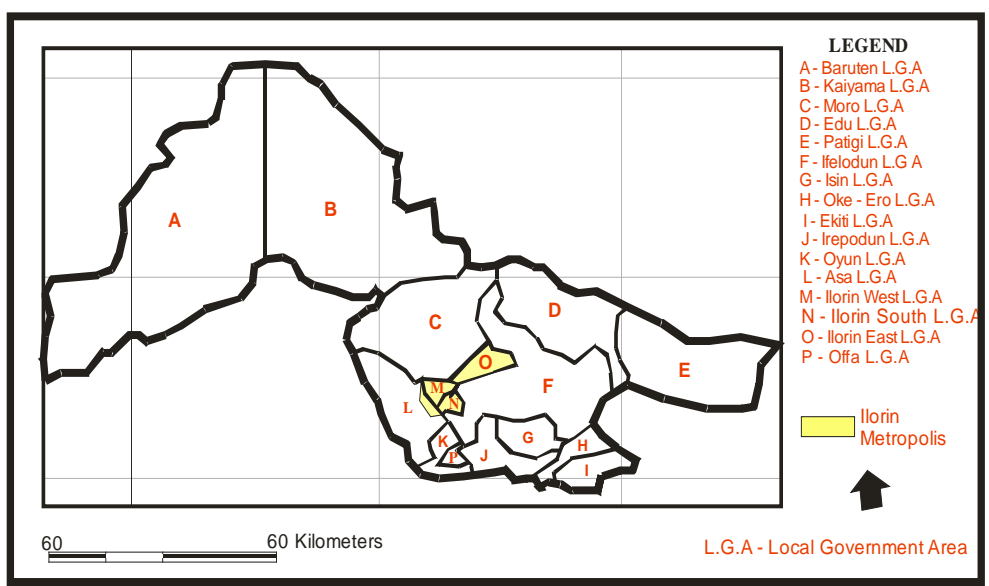

Figure 1. Ilorin metropolis in the context of Kwara State. Source: Kwara state town planning authority.

\subsection{Approach to Data Acquisition}

To help with mobility environment attribute contextualization, 10 local urban planning and transportation professionals were purposively selected from agencies and associated institutions in Ilorin metropolis. 6 of whom were field professionals and 4 from local tertiary institutions. The professionals helped extract contextually relevant factors from a list of 57 harvested potential mobility influencing attributes from literature. Note, that the 57 attributes are not entirely exhaustive, but were considered enough for Ilorin case. The rating of harvested attributes were done on a 5 point Likert scale ranging from 4 - 0 , with extremely significant having the highest and not significant the lowest. For instance, there is no formal bus system in Ilorin metropolis, hence the attribute scores ( 0 ) and ends up taken off the list. Only 7 of the 10 participating professionals were available for each of 3 contacts. Therefore, only ratings from these 7 were utilized for further analysis. The extraction of contextually relevant attributes were done by determining the weighted mean of entries for each item in the list of attributes to pave way for comparison to a calculated cut-off point. The cut-off point of acceptance or rejection of items rated in Likert scale is the arithmetic mean of individual weights [15], which in this case are 4, 3, 2, 1 and 0 . Hence, the cut-off point was calculated to be 2.00, Equation (1) shows the formula for this derivation. Consequently, any item with a weighted mean (WM) of 1.99 and below is considered not a significant contributor to mobility dilemma in the context of the study area, while those with $W M$ equal to or above 2.00 are considered significant. WM is derived as shown in Equation (2). The extraction of contextually relevant mobility influencing attributes was then done. Table 1 shows the $W M$ values of extracted contextually significant attributes for Ilorin metropolis.

$$
\begin{gathered}
\text { Cut-off point }=\frac{\sum_{i=1}^{n} W_{i}}{n}, \quad i=1,2,3, \cdots, n \\
W M=\frac{\sum_{i=1}^{n} W_{i} F_{i}}{n}, \quad i=1,2,3, \cdots, n
\end{gathered}
$$

Secondly, a general survey was carried out by trained research assistants with knowledge of the local language and terrain. Interviews were carried out in respondents' houses and in the streets of the constituent wards (spatial sub unit) of Ilorin, for which information is sought. Respondents were interviewed based on the checklist of 31 items that emerged from professional contextual ratings of potential mobility influencing attributes of Ilorin metropolis. Equal numbers of interviews were conducted in all wards, because the population figures at ward level are not officially available for the metropolis and for other cities in Nigeria at large. So, there were no bases for differing figures. 500 questionnaires were administered, based on [16] and [15], suggestions on sample size determination and in view of the population of the city which is, 510,444 persons. This translates into 25 questionnaires each per ward. As a precaution, an extra 5 questionnaire each were added to make 30 per ward, in order to make room for substitution in case some are returned unusable at the end of the city wide survey, which 
Table 1. List of extracted contextually relevant mobility influencing attributes for Ilorin metropolis.

\begin{tabular}{|c|c|c|c|c|c|c|c|c|}
\hline \multirow{2}{*}{ S/No } & \multirow{2}{*}{ ITEMS } & \multirow{2}{*}{$\begin{array}{c}4 \\
E S\end{array}$} & \multirow{2}{*}{$\begin{array}{c}3 \\
H S\end{array}$} & \multirow{2}{*}{$\begin{array}{l}2 \\
S\end{array}$} & \multirow{2}{*}{$\begin{array}{c}1 \\
L S\end{array}$} & \multirow{2}{*}{$\begin{array}{c}0 \\
N S\end{array}$} & \multirow{2}{*}{ Weighted Mean-WM } & \multirow{2}{*}{$\begin{array}{c}\text { Decision } \\
\text { R/NR }\end{array}$} \\
\hline & & & & & & & & \\
\hline 1 & Road Network Characteristics & 3 & 4 & 0 & 0 & 0 & 3.43 & $R$ \\
\hline 2 & Public transport cost & 5 & 1 & 1 & 0 & 0 & 3.57 & $R$ \\
\hline 3 & Public transport Fare/Distance relationship & 3 & 4 & 0 & 0 & 0 & 3.43 & $R$ \\
\hline 4 & Quality of public transport facilities & 1 & 3 & 3 & 0 & 0 & 2.71 & $R$ \\
\hline 5 & Land Use Mix & 5 & 2 & 0 & 0 & 0 & 3.71 & $R$ \\
\hline 6 & Activity Mix & 4 & 3 & 0 & 0 & 0 & 4.00 & $R$ \\
\hline 7 & Modal Variety & 3 & 2 & 2 & 0 & 0 & 3.14 & $R$ \\
\hline 8 & Private Modes & 5 & 2 & 0 & 0 & 0 & 3.71 & $R$ \\
\hline 9 & Congestion effect on mobility & 3 & 3 & 1 & 0 & 0 & 3.28 & $R$ \\
\hline 10 & Effect of time spent waiting at transport stops & 3 & 2 & 1 & 1 & 0 & 3.00 & $R$ \\
\hline 11 & Diversity of Movement Channels & 5 & 2 & 0 & 0 & 0 & 3.71 & $R$ \\
\hline 12 & Road Network Density & 6 & 1 & 0 & 0 & 0 & 3.85 & $R$ \\
\hline 13 & Pedestrian Network Density & 6 & 1 & 0 & 0 & 0 & 3.85 & $R$ \\
\hline 14 & Quality of public transport services & 2 & 2 & 2 & 1 & 0 & 2.71 & $R$ \\
\hline 15 & Public Transport Service Reliability & 4 & 2 & 1 & 0 & 0 & 3.43 & $R$ \\
\hline 16 & Delay factor & 3 & 1 & 2 & 1 & 0 & 2.86 & $R$ \\
\hline 17 & Safety attributes of Pedestrian Paths & 3 & 4 & 0 & 0 & 0 & 3.43 & $R$ \\
\hline 18 & Perceived Safety of bus stops & 2 & 3 & 2 & 0 & 0 & 3.00 & $R$ \\
\hline 19 & Traffic accidents & 2 & 3 & 2 & 0 & 0 & 3.00 & $R$ \\
\hline 20 & Road markings and signage & 2 & 4 & 0 & 1 & 0 & 3.00 & $R$ \\
\hline 21 & Development Density & 4 & 3 & 0 & 0 & 0 & 3.57 & $R$ \\
\hline 22 & Development Pattern & 3 & 3 & 1 & 0 & 0 & 3.28 & $R$ \\
\hline 23 & Public transport fare effect on monthly income & 4 & 2 & 1 & 0 & 0 & 3.43 & $R$ \\
\hline 24 & Public Modes & 3 & 2 & 2 & 0 & 0 & 3.14 & $R$ \\
\hline 25 & Number of transfers on routine trips to work/school/shopping & 2 & 3 & 2 & 0 & 0 & 3.00 & $R$ \\
\hline 26 & Public Transport Service Comfort & 2 & 3 & 1 & 1 & 0 & 2.86 & $R$ \\
\hline 27 & Distance from transport stops to your destination(s) & 4 & 2 & 1 & 0 & 0 & 3.43 & $R$ \\
\hline 28 & Distance to Public Transport stop at your origin & 4 & 2 & 1 & 0 & 0 & 3.43 & $R$ \\
\hline 29 & Average travel time to work/school/shopping & 3 & 2 & 2 & 0 & 0 & 3.14 & $R$ \\
\hline 30 & Pedestrian Network Characteristics & 3 & 2 & 2 & 0 & 0 & 2.20 & $R$ \\
\hline 31 & Fuel Affordability & 5 & 2 & 0 & 0 & 0 & 3.71 & $R$ \\
\hline
\end{tabular}

Where, ES extremely significant is 4 , HS, highly significant is 3 , S, significant is 2 , and LS, low significance is 1 and NS, not significant is 0 . WM represents Weighted Mean, while R denotes relevant Items respectively. For this study, the non-relevant factors were discarded. Only factors rated to be relevant were classified and used for further analysis and preparation for the next phase. 
usually is the case with survey based data collection exercises. Afterwards, 25 questionnaires were in turn randomly selected without replacement from the total number of valid questionnaires returned for each ward. The main issues of consideration in sampling for this research were geographic distribution, age, gender, employment status, income, location of activities of daily living and available human and financial resources to the researcher. The targeted age bracket was 18 - 65, normally considered active age range. Interviews were conducted along randomly selected streets. Approach to respondents' selection was systematic random sampling. Table 2 depicts the general socio-economic characteristics of respondents', while Table 3 summarizes frequency of each type of perceived effect reported by respondents'.

\section{Discussion}

As a prerequisite, the 31 contextually relevant potential attributes of influence to mobility perception in Ilorin metropolis were grouped according to trait similarities, since it is known that groups of attributes operate together to influence perception, as mentioned by [6]. For instance, all attributes describing development characteristics of the city are listed under one thematic area. This is necessary to allow for proper characterization of outcomes and comparison of effect. This exercise produced 7 thematic groups, listed A-G as in Table 4. Afterwards, the calculated weighted mean values for each attribute derived from ratings by respondents on another 5

Table 2. Socio-economic characteristics of respondents.

\begin{tabular}{|c|c|c|c|}
\hline Description & Class & Frequency & $\%$ composition \\
\hline \multirow{2}{*}{ Gender } & Male & 313 & 62.6 \\
\hline & Female & 187 & 36.4 \\
\hline \multirow{3}{*}{ Marital Status } & Total & 500 & 100 \\
\hline & Married & 248 & 49.6 \\
\hline & Single & 252 & 50.4 \\
\hline \multirow{6}{*}{ Age } & Total & 500 & 100 \\
\hline & $18-27$ & 217 & 43.4 \\
\hline & $28-37$ & 148 & 29.6 \\
\hline & $38-47$ & 95 & 19.0 \\
\hline & $48-57$ & 33 & 6.6 \\
\hline & 58 above & 7 & 1.4 \\
\hline \multirow{5}{*}{ Occupation } & Total & 500 & 100 \\
\hline & Civil Servant & 145 & 29.0 \\
\hline & Self Employed & 161 & 32.2 \\
\hline & Student & 165 & 33.0 \\
\hline & Unemployed & 29 & 5.8 \\
\hline \multirow{6}{*}{ Income Range } & Total & 500 & 100 \\
\hline & $0-\mathrm{N} 10,000$ & 161 & 32.2 \\
\hline & $\mathrm{N} 10,001$ - N20,000 & 105 & 21.0 \\
\hline & N20,001 - N30,000 & 92 & 18.4 \\
\hline & N30,001 - N40,000 & 87 & 17.4 \\
\hline & N40,001 and above & 55 & 11.0 \\
\hline \multicolumn{2}{|r|}{ Total } & 500 & 100 \\
\hline
\end{tabular}


Table 3. Respondents’ rating of contextually relevant mobility influencing attributes for Ilorin metropolis.

\begin{tabular}{|c|c|c|c|c|c|c|}
\hline \multirow{2}{*}{ S/No } & \multirow{2}{*}{ Attributes } & 1 & 2 & 3 & 4 & 5 \\
\hline & & HN & $\mathbf{N}$ & NPN & $\mathbf{P}$ & HP \\
\hline 1 & Diversity of movement channels & 104 & 100 & 97 & 96 & 103 \\
\hline 2 & Road network density & 92 & 110 & 97 & 88 & 113 \\
\hline 3 & Pedestrian network density & 100 & 96 & 105 & 87 & 112 \\
\hline 4 & Development density & 113 & 97 & 103 & 102 & 85 \\
\hline 5 & Development pattern & 95 & 103 & 109 & 80 & 113 \\
\hline 6 & Road characteristics & 108 & 99 & 95 & 96 & 102 \\
\hline 7 & Pedestrian network characteristics & 114 & 83 & 109 & 70 & 124 \\
\hline 8 & Quality of public transport facilities & 99 & 117 & 91 & 105 & 88 \\
\hline 9 & Land use mix & 103 & 84 & 110 & 110 & 93 \\
\hline 10 & Activity mix & 103 & 84 & 108 & 108 & 97 \\
\hline 11 & Modal variety & 89 & 104 & 85 & 97 & 125 \\
\hline 12 & Private modes & 23 & 47 & 88 & 165 & 177 \\
\hline 13 & Public modes & 181 & 129 & 114 & 34 & 42 \\
\hline 14 & Number of transfers on routine trips to work/school/shopping & 105 & 92 & 95 & 100 & 108 \\
\hline 15 & Average travel time to work/school/shopping & 106 & 108 & 86 & 86 & 114 \\
\hline 16 & Distance to public transport stop at your origin & 95 & 98 & 124 & 88 & 95 \\
\hline 17 & Distance from transport stops to your destination(s) & 108 & 92 & 112 & 86 & 102 \\
\hline 18 & Public transport cost & 111 & 104 & 102 & 96 & 87 \\
\hline 19 & $\begin{array}{l}\text { Public transport fare/distance } \\
\text { relationship }\end{array}$ & 123 & 103 & 93 & 74 & 107 \\
\hline 20 & Public transport fare effect on monthly income & 114 & 104 & 87 & 86 & 109 \\
\hline 21 & Fuel Affordability* & 89 & 31 & 19 & 24 & 27 \\
\hline 22 & Congestion effect on mobility & 117 & 110 & 89 & 93 & 90 \\
\hline 23 & Effect of time spent waiting at transport stops & 108 & 101 & 102 & 79 & 110 \\
\hline 24 & Public transport service reliability & 103 & 100 & 105 & 74 & 118 \\
\hline 25 & Public transport service comfort & 144 & 141 & 109 & 83 & 23 \\
\hline 26 & Delay factor & 100 & 120 & 105 & 78 & 97 \\
\hline 27 & Quality of public transport services & 104 & 94 & 108 & 91 & 103 \\
\hline 28 & Safety attributes of pedestrian paths & 274 & 65 & 51 & 91 & 19 \\
\hline 29 & Perceived safety of bus stops & 326 & 46 & 41 & 74 & 13 \\
\hline 30 & Traffic accidents & 106 & 120 & 97 & 68 & 109 \\
\hline 31 & Road Markings and signage & 134 & 98 & 89 & 82 & 97 \\
\hline
\end{tabular}

point Likert scale was done. Similar to the process utilized in the first stage, involving professional contextual relevance raters, a cut-off point of 3.00 was derived, representing the arithmetic mean of the representative numerical values for each of 5 types of descriptive effect of individual attribute perception. After comparing resultant $W M$ values with the cut-off point, it was evident that only 11 attributes of the 31 contextually relevant ones to Ilorin metropolis were perceived as positively influencing respondents' mobility. Therefore, it was concluded 
Table 4. Perception based rating of mobility influencing attributes of Ilorin metropolis.

\begin{tabular}{|c|c|c|c|c|c|c|}
\hline S/No & Attribute Description & \multirow{2}{*}{$\sum W_{i} F_{i}$} & \multirow{2}{*}{$n$} & \multirow{2}{*}{$\frac{\sum W_{i} F_{i}}{n}$} & \multirow{2}{*}{ Rank Order } & \multirow{2}{*}{$\begin{array}{c}\text { Type of } \\
\text { perception }\end{array}$} \\
\hline$A$ & Network Characteristics & & & & & \\
\hline 1 & Diversity of movement channels & 1494 & 500 & 2.988 & $12^{\text {th }}$ & $\mathbf{N}$ \\
\hline 2 & Road network density & 1520 & 500 & 3.040 & $3^{\text {rd }}$ & $\mathbf{P}$ \\
\hline 3 & Pedestrian network density & 1515 & 500 & 3.030 & $4^{\text {th }}$ & $\mathbf{P}$ \\
\hline B & Development Characteristics & & & & & \\
\hline 4 & Development density & 1449 & 500 & 2.898 & $22^{\text {nd }}$ & $\mathbf{N}$ \\
\hline 5 & Development pattern & 1513 & 500 & 3.026 & $6^{\text {th }}$ & $\mathbf{P}$ \\
\hline 6 & Road characteristics & 1485 & 500 & 2.970 & $15^{\text {th }}$ & $\mathbf{N}$ \\
\hline 7 & Pedestrian network characteristics & 1507 & 500 & 3.014 & $8^{\text {th }}$ & $\mathbf{P}$ \\
\hline 8 & Quality of public transport facilities & 1466 & 500 & 2.932 & $19^{\text {th }}$ & $\mathbf{N}$ \\
\hline$C$ & Density of opportunity & & & & & \\
\hline 9 & Land use mix & 1506 & 500 & 3.012 & $9^{\text {th }}$ & $\mathbf{P}$ \\
\hline 10 & Activity mix & 1512 & 500 & 3.024 & $7^{\text {th }}$ & $\mathbf{P}$ \\
\hline$D$ & Mode characteristics & & & & & \\
\hline 11 & Modal variety & 1565 & 500 & 3.130 & $2^{\text {nd }}$ & $\mathbf{P}$ \\
\hline 12 & Private modes & 1926 & 500 & 3.852 & $1^{\text {st }}$ & $\mathbf{P}$ \\
\hline 13 & Public modes & 1127 & 500 & 2.254 & $27^{\text {th }}$ & $\mathbf{N}$ \\
\hline $\boldsymbol{E}$ & Travel characteristics & & & & & \\
\hline 14 & $\begin{array}{l}\text { Number of transfers on routine trips to } \\
\text { work/school/shopping }\end{array}$ & 1514 & 500 & 3.028 & $5^{\text {th }}$ & $\mathbf{P}$ \\
\hline 15 & Average travel time to work/school/shopping & 1494 & 500 & 2.988 & $12^{\text {th }}$ & $\mathbf{N}$ \\
\hline $\boldsymbol{F}$ & Transport accessibility factors & & & & & \\
\hline 16 & Distance to public transport stop at your origin & 1490 & 500 & 2.980 & $14^{\text {th }}$ & $\mathbf{N}$ \\
\hline 17 & Distance from transport stops to your destination(s) & 1482 & 500 & 2.964 & $16^{\text {th }}$ & $\mathbf{N}$ \\
\hline G & Economic factors & & & & & \\
\hline 18 & Public transport cost & 1444 & 500 & 2.888 & $23^{\text {rd }}$ & $\mathbf{N}$ \\
\hline 19 & Public transport fare/distance relationship & 1439 & 500 & 2.878 & $24^{\text {th }}$ & $\mathbf{N}$ \\
\hline 20 & Public transport fare effect on monthly income & 1472 & 500 & 2.944 & $18^{\text {th }}$ & $\mathbf{N}$ \\
\hline 21 & Fuel Affordability ${ }^{*}$ & 439 & 191 & 2.298 & $31^{\mathrm{st}}$ & $\mathbf{N}$ \\
\hline $\boldsymbol{H}$ & Operational Characteristics & & & & & \\
\hline 22 & Congestion effect on mobility & 1426 & 500 & 2.852 & $25^{\text {th }}$ & $\mathbf{N}$ \\
\hline 23 & Effect of time spent waiting at transport stops & 1482 & 500 & 2.964 & $16^{\text {th }}$ & $\mathbf{N}$ \\
\hline 24 & Public transport service reliability & 1504 & 500 & 3.008 & $10^{\text {th }}$ & $\mathbf{P}$ \\
\hline 25 & Public transport service comfort & 1034 & 500 & 2.068 & $28^{\text {th }}$ & $\mathbf{N}$ \\
\hline 26 & Delay factor & 1452 & 500 & 2.904 & $21^{\text {nd }}$ & $\mathbf{N}$ \\
\hline 27 & Quality of public transport services & 1495 & 500 & 2.990 & $11^{\text {th }}$ & $\mathbf{N}$ \\
\hline$I$ & Safety factors & & & & & \\
\hline 28 & Safety attributes of pedestrian paths & 1016 & 500 & 2.032 & $29^{\text {th }}$ & $\mathbf{N}$ \\
\hline 29 & Perceived safety of bus stops & 902 & 500 & 1.804 & $30^{\mathrm{st}}$ & $\mathbf{N}$ \\
\hline 30 & Traffic accidents & 1454 & 500 & 2.908 & $20^{\mathrm{st}}$ & $\mathbf{N}$ \\
\hline 31 & Road Markings and signage & 1410 & 500 & 2.82 & $26^{\text {th }}$ & $\mathbf{N}$ \\
\hline
\end{tabular}


that the remaining 20 attributes were each contributors to mobility dilemma in the city.

Regarding perception of individual thematic groups, the development characteristics thematic area, with 10 different attributions had 6 of them, namely, pedestrian network density, pattern of development, road characteristics, pedestrian network characteristics, land use mix and activity mix all perceived positively. Pedestrian network density and pedestrian network characteristics represent differing attributions in that the former refers to the concentration of pedestrian networks, while the latter describes their physical characteristics, such as surfacing. However, diversity of movement channels, road network density, development density and quality of public transport facilities (which in this case refers only to bus stops) were considered a source of mobility dilemma. Road characteristics ranked $9^{\text {th }}$, with a weighted mean value of 3.014, an indication that respondents' percept was positive. Even though, the roads are most often plagued with structural and functional lapses that threaten motorized and non-motorized traffic safety [17]. Signifying acceptance of prevalent road conditions as they are, instead of what they should be in terms of standards. This might also be tied to the fact that $95 \%$ of urban trips in Nigeria are made by roads, according to [18], therefore it appears that road users have become captive such that functionality trumps standards. This notion is accentuated by a similar overall positive perception of pedestrian network characteristics of the city, mainly made up of unpaved residual spaces adjoining roads and in-between buildings. This shows that majority of the respondents' are not enlightened about what to expect regarding roads and pedestrian facilities, therefore, they appear to be under reporting the degree to which such attributions affect the level of mobility stress they might be experiencing. The import of this is that most city travelers in Ilorin have adapted to making do with what is available, and not what is desirable.

The development density of the city was largely perceived negatively. Contrarily, the pattern of development was adjudged to be a positive influencing attribute of mobility. Here lies another contradiction, because the development density of Ilorin metropolis has been reported to be high for the most part [11], a situation that is supposed to be favourable to pedestrian movement, given the relatively low personal mobility ownership level in the city. Only 191 persons of the 500 respondents' own personal means of transportation. Furthermore, the quality of public transport facilities was deemed to be negative, it turned up with a 2.932 weighted mean and a ranking of $20^{\text {th }}$, of the 31 contextually relevant attributes. It should be noted that, public transport facilities refer almost entirely to improvised stop areas, except for very few that are actually officially designated as bus stops. Therefore, the main highlighting factor of mobility dilemma in terms of development characteristics in Ilorin metropolis can be connected to inadequate planning and substandard supply of transport facilities. Two other issues seen to be contributing to mobility dilemma in Ilorin metropolis that are also tied to the cities development characteristics are distance to public transport stops at origins and distance from public transport stops at destinations. These two public transport accessibility attributes of the mobility environment of Ilorin metropolis were considered to be negatively affecting the perception of mobility in the city by the respondents', thereby contributing to mobility distress. They both turned in a weighted mean of less than 3.00.

As for ratings of modal characteristics, respondents' attributed a positive effect to use of private modes, it turned up with a weighted mean value of 3.852, thereby ranking $1^{\text {st }}$, in terms of level of positive influence on respondents' mobility. This agrees with assertions in the literature that private means of movement are usually preferred by travelers, unless conscious efforts are instituted to reduce its use from several fronts, in order to reduce the side effects of over motorization, which usually adds to mobility dilemma, often compounded by inadequate planning, as was the case for Ilorin metropolis. The complete absence of comprehensive and integrated public transit system [19], ensures that private modes are preferred over public modes. A situation affirmed by the ranking of public mode attributes as $27^{\text {th }}$ of all 31 contextually relevant attributes that contributes to mobility distress in the study area. This is a worrisome development because according to [19], 70\% of urban trips are made by public transport modes, the high ridership happens mostly for lack of alternatives, not by choice, meaning that the highly negative percept of influence of public modes will likely define how mobility is generally perceived in the metropolis. This is even more so that all respondents' including the 191 with personal means of mobility use public modes from time to time. The availability of a variety of modes to choose from was however seen to be a positive influence on respondents' mobility in the study area. Even though the array only includes, cars, motorcycles, rickshaws and minibuses, that are ill-maintained and rickety and serviced by equally deplorable auxiliary facilities (if any), reflective of a highly decentralized and poorly regulated sector, due mainly to private ownership of all public transport modes in the metropolis. This attribute of public modes ownership also explains the possibility of having diverse characteristics in public transportation within the city [20]. This is underlined by the fact that some areas are serviced by only rickshaws, or motorcycles, or taxis or 
minibuses, while others are served by a combination of taxis, minibuses, and motorcycles, leading to a different array of public transport mode choices available for different parts of the city. Off the three attributes that defines mode characteristics in the metropolis, only public modes attributes were perceived negatively, see Table 4.

In economic terms, overall public transport cost is negatively affecting perception of mobility according to the respondents'. This stance is further buttressed by the fact that, public transport fare/distance relationship and public transport fare effect on monthly income were both seen as unfavourable. More so, fuel affordability, as perceived by $38.2 \%$ of respondents' with private means of mobility was also negative. If the prevailing attributions of the economic aspects of mobility in Ilorin metropolis are viewed against the backdrop of [21] assertion that, exorbitant prices of spare parts and inability of the largely unregulated private operators to purchase new vehicles to expand their fleet, coupled with the negative perception of overall transport cost by respondents', it becomes clear that, both the informal operators of public transportation and the travelers are operating in a distressful environment, wherein none of the parties is favoured. In the same vein, the perception of contextually relevant attributes that describe mobility safety in the city, namely safety characteristics of pedestrian paths, safety of bus stops, rate of traffic accidents and the deployment of road markings and signs, were all negative. This confirms as mentioned before, that in general terms roads in Nigeria are for the most part improperly designed, thereby unsafe, while the equipment used by the operators also aggravate safety issues [22].

\section{Conclusion}

Grasping issues around determinant factors of individual mobility experiences, are important in understanding how elements an individual is exposed to shape their percept of mobility, and the extent to which they contribute to associated dilemma, because the variability of reasons for an individual's own choice of how and when to move, or where to go is huge. Thus, perception based studies could provide versatile input into the assessment of public mobility space by segmenting preferences. More so, it is the individual's perception of the environment that defines what that individual considers the action space, which is the area within which opportunities may be easily reached by individuals for their activities [23]. The knowledge that, through the perceptual process, we gain information about properties and elements of the environment that are critical to our survival, underscores the increasing significance of perception based studies. Upon which the prospect of detecting environmentally induced mobility complexities from traveler perception is premised, especially where use of other sophisticated means of evaluation might be improbable. Specifically, it became apparent that attributes of public modes, development characteristics, as well as operational, economic and safety attributions of the city's mobility environment were influencing perception of mobility by respondents' negatively, mainly as an offshoot of inadequate planning and regulation enforcement in the city. It is suggested that, simplistic parsimonious techniques such as utilized in this work, be employed in bridging the gap between comprehensive plans, where wherewithal is lacking. This work demonstrates with Ilorin, a typical metropolitan area in north central Nigeria, how perception based determinants of mobility dilemma were isolated and processed to yield information about mobility environment induced distress, derived from perception of mobility influencing attributes inherent in an individual's mobility environment.

\section{References}

[1] Ravenstein, E.G. (1885) The Laws of Migration. Journal of the Statistical Society of London, 48, 167-235.

[2] Noulas, A., Scellato, S., Lambiotte, R., Pontil, M. and Mascolo, C. (2012) A Tale of Many Cities: Universal Patterns in Human Urban Mobility. PLoS ONE, 7, e37027. http://dx.doi.org/10.1371/journal.pone.0037027

[3] Hong, S. (2010) Human Movement Patterns, Mobility Models and Their Impacts on Wireless Applications. A Dissertation Submitted to the Graduate Faculty of North Carolina State University in Partial Fulfillment of the Requirements for the Degree of Doctor of Philosophy Computer Science Raleigh, North Carolina.

[4] Isaacman, S., Becker, R., Caceres, R., Martonosi, M., Rowland, J., Varshavsky, A. and Willinger, W. (2012) Human Mobility at Metropolitan Scales. 10th International Conference on Mobile Systems (MobiSys'12), 25-29 June 2012, Low Wood Bay, Lake District, United Kingdom.

[5] Kovalik, C. and King, M.E. (1998) Visual Literacy. http://www.educ.kent.edu/community/VLO

[6] Sokolowska, K. (2014) Determinants and Perceptions of Social Mobility in Poland, 1992-2008. Contemporary Economics, 8, 89-109. 
[7] Merikle, P.M. and Reingold, E.M. (1992) Measuring Unconscious Perceptual Processes. In: Bornstein and Pittman, Eds., Perception without Awareness, Guilford Publications, New York, 55-80.

[8] Aarts, M. J., Mathijssen, J.P., van Oers, J.M. and Schuit, A. (2013) Associations between Environmental Characteristics and Active Commuting to School among Children: A Cross-Sectional Study. International Journal of Behavioural Medicine, 20, 538-555. http://dx.doi.org/10.1007/s12529-012-9271-0

[9] Cole, R., Burke, M., Leslie, E., Donald, M. and Owen, N. (2010) Perceptions of Representatives of Public, Private and Community Sector Institutions of Barriers and Enablers of Physical Active Transport. Transport Policy, 17, 496-504. http://dx.doi.org/10.1016/j.tranpol.2010.05.003

[10] Alton, D., Adab, P. and Barret, T. (2007) Relationship between Walking Levels and Perceptions of the Local Neighbourhood Environment. Archives of Diseases in Childhood, 92, 29-33. http://dx.doi.org/10.1136/adc.2006.100826

[11] Ahmed, Y.A. (1996) Problems of Physical Planning in Ilorin City, Nigeria. Msc. Dissertation, Department of Geography, University of Ilorin, Ilorin.

[12] Aderamo, A.J. (2000) City Planning and Management Techniques. In: Jimoh and Ifabiyi, Eds., Contemporary Issues in Environmental Studies, University Press, Ilorin, 32-43.

[13] Aderamo, A.J. (2003) Changing Structure of Intra-Urban Road Network in Ilorin Nigeria (1963-1999). Ilorin Journal of Business and Social Sciences, 8, 65-76.

[14] Aderamo, A.I. (2008) Urbanization and Transportation in Nigeria. In: Mamman, A.B., Chup, C.D. and Mashi, S.A., Eds., Urbanization, Resource Exploitation and Environmental Stability in Nigeria, Joyce Graphic Printers and Publishers, Kaduna, 55-65.

[15] Morenikeji, W. (2006) Research and Analytical Methods. Jos University Press Ltd, Jos.

[16] Veal, A.J. (2006) Research Methods for Leisure and Tourism. 3rd Edition, Prentice Hall, London.

[17] Shittu, A.O. (2013) Exploring Pedestrian Challenges and Safety Experience along Samaru-Shika Transport Corridor in Zaria. Construction Focus (ABU, Zaria), 2, 29-38.

[18] Oyesiku, O.K. (2002) Policy Framework for Urban Motorcycle Public Transport System in Nigerian Cities. In: Godard, X. and Innocent, F., Eds., Urban Mobility for All, A. A., Lisse, Balkema, 255-261.

[19] Filani, M.O. (2002) Mobility Crisis and the Federal Government’s Mass Transit Programme. In: Onakomaiya, S.O. and Oyesiku, O.O., Eds., Environment, Physical Planning and Development in Nigeria, Department of Geography and Regional Planning, Olabisi Onabanjo University, Ago-Iwoye, 37-51.

[20] Shittu, A.O. (2014) Towards Quasi-Formal Management of Paratransit in Informal Transport Dependent Cities of Nigeria. IOSR Journal of Humanities and Social Science (IOSR-JHSS), 19, 75-80. http://dx.doi.org/10.9790/0837-191247580

[21] Asiyanbola, R.A. (2007) Intra-Urban Transportation, Gender and Psychological Distress in Developing Countries: Nigeria. A paper submitted for presentation at the Workshop on: Urban Population, Development and Environment dynamics in developing countries, organized by the Committee for International Cooperation in National Research in Demography (CICRED), in collaboration with the Population-Enviroment Research Network (PERN) and the Center for International Earth Science Information Network (CIESIN) of Columbia University, 11-13 June 2007, Nairobi, Kenya.

[22] Shittu. A.O. (2011) In-Transit Factors Affecting Minibus Ride Perception in Zaria Urban Area. Centre for Human Settlements and Urban Development Journal (CHSUDJ, FUT Minna), 2, 28-40.

[23] Dijst, M., Schenkel, W. and Thomas, I. (2002) Governing Cities on the Move, Functional and Management Perspectives on Transformations of European Urban Infrastructures. In: Urban and Regional Planning and Development, Ashgate Publishing Limited, Aldershot. 